\title{
Adaptation to climate change of Moroccan companies: towards an appropriate climate risk anticipation tool
}

\author{
Youssef Jaouhari ${ }^{1 *}$, Laila Stour $^{1}$, Ali Agoumi ${ }^{2}$ \\ ${ }^{1}$ Process and Environment Engineering Laboratory, Faculty of Sciences and Techniques of Mohammedia, Hassan II University of \\ Casablanca, B.P. 146, Mohammedia, Morocco. \\ ${ }^{2}$ Civil Engineering, Hydraulics, Environment and Climate Change Laboratory, Hassania School of Public Works, Casablanca, \\ Morocco. Email: agoumi.ali@gmail.com
}

\begin{abstract}
In a fragile and unpredictable economic and health context, Climate Change (CC) is emerging as an eminent issue for businesses in Morocco. This planetary scourge is a double-edged issue. It exacerbates the vulnerability of these companies by affecting the supply of raw materials, energy, and water. It can also be an opportunity for companies that opt for innovative mitigation and adaptation solutions to address CC. Today, the tools and approaches for monitoring greenhouse gas (GHG) emissions are relatively standardized and known. However, the methods used to characterize vulnerability and develop adaptation strategies remain limited and little known. To this end, the Climate Expert tool $(\mathrm{CE})^{\dagger}$ has been tested on a panel of Moroccan companies to enable them to characterize their vulnerability to $\mathrm{CC}$ and to develop relevant adaptation strategies. A global and detailed analysis was carried out on the evaluation reports, the results of a targeted survey, and completed by a SWOT ${ }^{*}$ analysis on the consistency and use of the CE tool. Three groups of interlocutors were involved in this analysis: CE experts, economic operators, and state and project officials. To better plan adaptation measures, this analysis emphasizes the need to move the approach proposed by CE towards an integrated, standardized design. In addition, the implementation of adaptation requires, in particular the setting up of support and advisory instruments and entities in charge of steering adaptation actions within companies. The next stage of this work will be devoted to improving and adapting the $\mathrm{CE}$ tool to meet the needs of concrete actions in such companies to deal with $\mathrm{CC}$.
\end{abstract}

\section{Introduction}

In Morocco, small and medium enterprises (SMEs) are a central component of the national economy, which represents nearly $93 \%$ of the productive fabric (HCP 2019). They are a real engine of job creation and contribute $40 \%$ of private investment and $30 \%$ of exports [1]. However, this network of economic actors forms a heterogeneous sector weighed down by a set of obstacles that prevent its full development. These obstacles mainly relate to the difficulty of obtaining financing, competition from the informal sector, and in some cases, the lack of managerial skills within these companies [1], [2].

Given its strategic choices to be part of globalization and the opening of its economy, Morocco is led to increase its economic attractiveness and strengthen its competitiveness and direct foreign investments [3], [4]. Thus, Moroccan companies are involved in an approach that takes into account the societal dimension. This is reflected by using ISO 9001 certification standards for quality management and ISO14001 for environmental management, as well as corporate social responsibility approaches (CSR), integrating social, environmental, and economic concerns into their management activities. [5].

In this context, the CC stands today as an eminent issue for Moroccan companies, in particular for SMEs. It has multiple impacts that can affect all links in the value chain, in particular facilities, the production process, employees, and even the supply chain [6], [7].

$\mathrm{CC}$ represents the archetype of a new type of risk that companies are called upon to manage [8], [9]. These companies are already experiencing a set of CC-induced impacts ranging from increased operating costs to production disruption [10]. During the last decades, Moroccan companies have faced a series of climatic events, which have affected their supplies (raw materials, energy, and water), extreme climatic phenomena (floods, drought, etc.), as well as the degradation of working conditions due to heatwaves or the spread of infectious diseases [7], [11], [12].

To explore the perception of Moroccan entrepreneurs, a survey was conducted in 2016 on their perception of climate risk [13]. This survey showed that the quasi-majority of the interviewees consider that the risk is "high to medium" respectively for the following areas: logistics and stock, employees and community,

\footnotetext{
${ }^{*}$ Corresponding author: youssef.jaouhari@gmail.com

${ }^{\dagger}$ Tool developed by the German International Development Cooperation Agency (GIZ).

* SWOT (Strengths | Weaknesses | Opportunities | Threats)
} 
market and process. For other areas, the risk is considered low to non-existent [14]. On the side of the federations affiliated to the General Confederation of Moroccan Enterprises (CGEM), a recent survey on the gap between theoretical sensitivity to $\mathrm{CC}$ and that perceived, underlined that actors in the sectors of agriculture, tourism, and fisheries see themselves as more vulnerable to climate risks and therefore more concerned with adaptation to $\mathrm{CC}$ [11].

Concept of climate-related risk: The Fifth Assessment Report (AR5) of the Intergovernmental Panel on Climate Change (IPCC) [15] introduced a new concept that aims to identify and assess the risks of CC impacts. This report defined risk as: "the potential for consequences where something of value is at stake and where the outcome is uncertain, recognizing the diversity of values". According to this new concept, the risk of CC impacts arises from the interaction between climatic hazards (including trends and extreme events) and the vulnerability and exposure of anthropogenic and natural systems. In line with the IPCC definition, risk is then assessed as a combination of hazard, vulnerability and exposure. Generally, adaptation measures can reduce the risk by reducing vulnerability and in certain cases also exposure (Fig. 1).

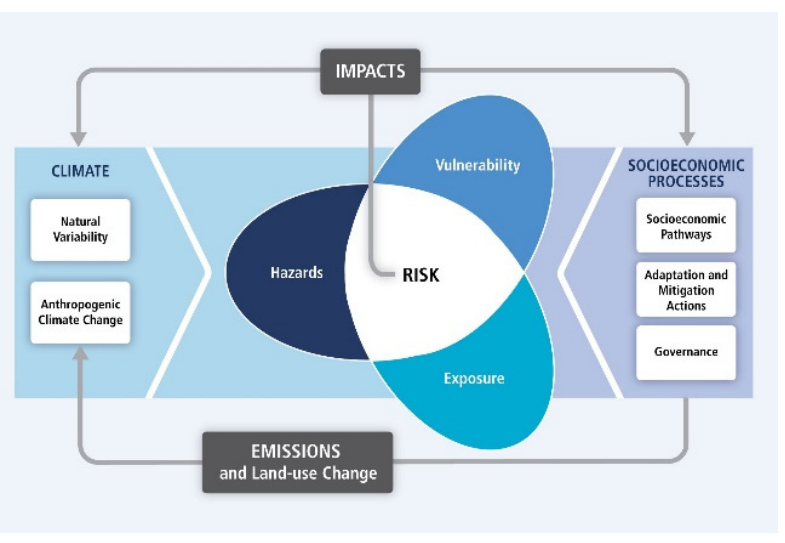

Figure 1. Illustration of the core concepts of the IPCC WGII AR5 [15]

Climate risk represents a long-term issue that often goes beyond the usual management horizon of companies. Businesses have been able to integrate the mitigation situation as best they can, but their role in adaptation is not widely understood. It is often deemed the responsibility of the state [16]. The anchoring of adaptation in the business world necessarily depends on three main levers: political support, mobilization of human and financial resources, and mainstreaming of adaptation in strategies and decisions using appropriate approaches [17].

Methodologically, while GHG emission-accounting tools and standards are relatively standardized and known, those available to characterize vulnerability and assess risks induced by $\mathrm{CC}$ are limited and nonstandardized. Taking into account the above, this article analyzes and puts into perspective the feedback on the consistency of the CE tool and its use by a panel of Moroccan companies to characterize their vulnerability to $\mathrm{CC}$ and to implement appropriate adaptation strategies. It also defines and proposes ways of improving the structure and use of the CE tool to make it more compatible with the needs of SMEs in Morocco and possibly in developing countries

\section{Materials and methods}

\subsection{Climate Expert (CE) tool}

To fill the above-mentioned methodological gap, the German International Development Cooperation Agency (GIZ) has designed a decision support tool for companies, called Climate Expert (CE), which includes a Multi-Criteria Analysis (MCA), a risk prioritization grid, and optionally a Cost-Benefit Analysis (CBA). Through a focus on $\mathrm{CC}$, this tool enables companies to better identify their vulnerabilities and business opportunities, assess and prioritize their risks, and put in place a response strategy including effective and efficient adaptation measures [18]. Following a practice-oriented approach to adaptation, the CE tool is structured around four successive steps, preceded by a preliminary general assessment step (Fig. 2):

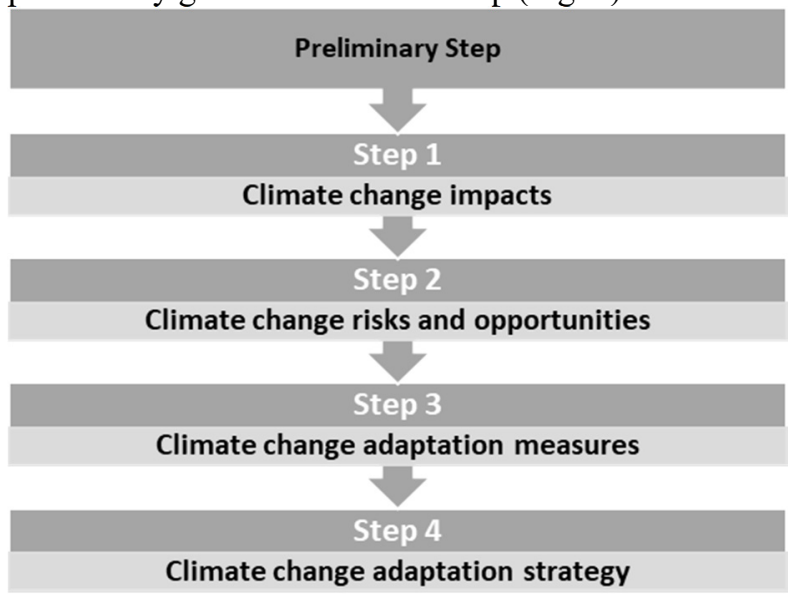

Figure 2. Steps of the Climate Expert process [18]

This tool has been tested in the Moroccan business context through a series of case studies covering about twenty Moroccan companies, operating in the agribusiness and textile sectors. And this, under the technical assistance of the ASPCC A $^{\S}$ programs and that of International Trade Center (ITC) entitled "Strengthening competitiveness and climate resilience in the value chain of Moroccan companies". These programs made their network of experts and their methodological corpus available to the selected companies [19], [20].

\subsection{Methodological approach}

According to a capitalization approach aimed at strengthening organizational learning [21], [22] of companies in terms of adaptation to $\mathrm{CC}$, this research work was organized according to the following steps: 
- An analysis based on the outputs resulting from various evaluation missions using the CE tool with Moroccan companies. The studies and evaluations conducted in Morocco in connection with the issue of adaptation of the private sector served to consolidate the results of this analytical work.

- A survey was prepared and shared with the CE experts. The sections of this survey focused on the following aspects: mastery of the CE process, consistency and use of the tool, and proposals for improving the tool.

- Based on the responses to the survey, a SWOT analysis was carried out taking into account the two fields of analysis:

* The first so-called "internal" field, specific to the $\mathrm{CE}$ tool, and which concerns the mastery of the CE tool, its relevance, and the consistency of its steps. At this level, the analysis attempted highlighting the strengths and weaknesses intrinsic to the tool;

* The second field, called "external", covers aspects related to the use of the tool by focusing on the opportunities likely to promote demand and effective use of the tool. This field is also interested in threats likely to reduce the efficiency of use and the interest of companies in the tool.

\section{Results and discussion}

\subsection{SWOT analysis results}

The CE tool has many advantages, both in terms of its logical, simple and intuitive structure, and its ability to adapt to different sectors of activity, regardless of the size of the company. The tool's designers have emphasized the exchanges and contributions (expert/managers) throughout the deployment of the tool's stages, by providing participatory decisionmaking tools (MCA, CBA, and risk ranking table).

However, case studies highlighted several weaknesses inherent to the $\mathrm{CE}$ that sometimes makes the conduct of certain stages of the process hazardous and time-consuming. These are essentially the conceptual framework, which needs to be made consistent with that proposed by the IPCC in its fifth assessment report [17]. The terminology related to this framework (risk, vulnerability, adaptation, etc.) must be specified and used appropriately. The tool also lacks elements that would document each step and offer choices following the context of Moroccan companies. This could make the tool much easier to use for people with an average $\mathrm{CC}$ background.

As for the use of the CE tool, the main threats can be summarized as the challenge of the approach appropriation by top management - given its central role in the conduct of the approach and the implementation of its outputs -, the availability of relevant climate data for the identification of climate risks at the enterprise level, and the need to provide post-evaluation support. In addition, the opportunities offered using such an approach are multiple. These include the role of the tool in facilitating adaptation planning and promoting corporate compliance with new regulations.
Table. 1. Results of the SWOT analysis.

\begin{tabular}{|c|c|}
\hline Fields & Strengths \\
\hline & $\begin{array}{l}\text { - Relatively easy to learn and to master } \\
\text { - Widely used software support (MS } \\
\text { Excel) } \\
\text { - A logical and intuitive sequence of } \\
\text { steps } \\
\text { - Average workload } \\
\text { - The affordable cost of expertise } \\
\text { - An approach based on the participation } \\
\text { of company managers } \\
\text { - ABC optionally integrated into the tool }\end{array}$ \\
\hline & Weaknesses \\
\hline $\begin{array}{l}\text { Consistency } \\
\text { of the CE } \\
\text { tool }\end{array}$ & $\begin{array}{l}\text { - Conceptual framework and related } \\
\text { terminology must be clarified and used } \\
\text { wisely } \\
\text { - Generic training modules } \\
\text { - Lack of links to additional resources in } \\
\text { the tool } \\
\text { - Lack of pre-established choices with a } \\
\text { standard formulation (drop-down lists, } \\
\text { etc.) } \\
\text { - The rapid assessment step is not } \\
\text { entirely justified } \\
\text { - Deficiency in framing and } \\
\text { documentation of steps } \\
\text { - Time-consuming MCA (many criteria) } \\
\text { - Weak integration of the } \\
\text { adaptation/mitigation co-benefit aspect } \\
\text { - Analysis of climate opportunities as a } \\
\text { poor relation of the process }\end{array}$ \\
\hline \multirow{4}{*}{$\begin{array}{l}\text { Use of the } \\
\text { CE tool }\end{array}$} & Opportunities \\
\hline & $\begin{array}{l}\text { - New favorable regulations (polluter } \\
\text { pays) } \\
\text { - Possibility of developing an integrated } \\
\text { climate strategy for the company (GHG } \\
\text { assessment }+ \text { CE tool) } \\
\text { - Positive impact for the company in } \\
\text { terms of image and international } \\
\text { reputation } \\
\text { - Multiple opportunities offered by the } \\
\text { mechanisms of climate finance }\end{array}$ \\
\hline & Threats \\
\hline & $\begin{array}{l}\text { - Availability of relevant climate data at } \\
\text { the sector/company level } \\
\text { - The involvement of top management is } \\
\text { decisive } \\
\text { - Implementation of adaptation measures } \\
\text { often depends on adequate post- } \\
\text { assessment support and the provision of } \\
\text { a financing plan } \\
\text { - Lack of a structured expert network to } \\
\text { ensure wide dissemination of the CE } \\
\text { approach }\end{array}$ \\
\hline
\end{tabular}




\subsection{Determinants of an appropriate tool for Moroccan companies}

The results of the analysis agree on some characteristics that should guide the task of reviewing and improving a CE tool. These are specifically:

- Robust approach: Based on a clear and simple conceptual framework with a terminological focus inspired by the IPCC methodological corpus.

- Mixed approach: based on the integration of the results of the top-down and bottom-up approaches. For climate studies, mixed approaches make it possible to generate additional information on climate-related risk in all its dimensions [23]. At the scale of a company or an industrial area, this crossing and cross-checking of climate information are particularly relevant to meet the real needs of immediate adaptation decisions.

- Flexible and tailored approach to the types of companies: the methodological approach can be shaped to the information needs and the level of detail sought by the company in question, to characterize its vulnerabilities and its climate risk. This need differs according to the size of the company (very small businesses, SMEs, or large companies) and the degree of vulnerability of its sector of activity. In this regard, the tool can recommend different paths depending on the level of analysis desired.

- Solution-oriented approach: On an operational level, adaptation for a company is supposed to offer concrete and effective solutions that can reduce the risks and seize the possible opportunities offered by CC. Steps 3 and 4 of the CE process should allow to find and prioritize appropriate adaptation measures explicitly. It would also be appropriate to categorize the range of adaptation options according to their potential impacts or risks, based on in-depth reflection. Thus, the agreed coping strategies can be classified as no-regret strategies, reversible strategies, safety margin strategies, or soft strategies [24].

- Approach taking into account the uncertainty inherent in adaptation: The issue of uncertainty can be seen as a potential barrier to adaptation action. The interviewed companies affirm that they would be more reactive in anticipating adaptation actions if they had a piece of more reliable information on the subject. However, given its relation to the future development of climatic and socioeconomic systems, adaptation to $\mathrm{CC}$ is intrinsically characterized by action in a context of marked uncertainty, even deep uncertainty [25]. From this perspective, the approach must imperatively foresee the possibility of using uncertainty analysis tools to better inform decision-making frameworks.

- Iterative learning approach: Most of the interviewed companies focus on specific aspects of $\mathrm{CC}$, particularly carbon reduction and water and energy use. Companies engaged in a reflection in terms of risks and opportunities remain a minority [14]. The adaptation takes place in a dynamic environment under the influence of changing external and internal factors [25]. This requires that the approach adopts an iterative logic that can embed adaptation within the firm in a continuous learning process, to achieve acceptable adaptation strategies that effectively meet the needs of the company.

\section{Conclusion and prospects for improving CE tool}

For a company, adaptation implies reviewing its management modes and practices and its business operations to limit negative impacts and better exploit potential opportunities generated by CC [26]. However, the task of integrating adaptation into the business is one in which standards and methodologies are not yet fully stabilized. In the Moroccan context, the CE tool has been popularized among some twenty Moroccan companies operating mainly in the textile and agri-food sectors. Based on the feedback and analysis of the existing tool, this research work has attempted to examine possible improvements to standardize and align the design of the CE tool with the real objectives and needs of Moroccan companies. In this quest to improve the tool, it would be useful to:

- Review the conceptual framework adopted for the tool to make it clearer and easier to understand;

- Adopt a mixed approach to make the best use of the bottom-up information acquired and accumulated within the company;

- Shape the risk analysis paths according to the size and degree of vulnerability of the companies;

- Improve the prioritization of adaptation options to facilitate their subsequent implementation;

- Strengthen the aspects related to the analysis and management of uncertainties;

- Include the tool in a continuous learning process.

In short, this analysis has highlighted the importance of developing an improved version of the $\mathrm{CE}$ tool to address the identified lacks and provides adequate answers to the needs expressed by the companies. However, it is useful to recall that the issue of implementing adaptation within companies also requires the establishment of support and advisory instruments and entities in charge of steering the adaptation [14].

The next stage of this research will be dedicated to the improvement and remodeling of the CE tool to meet the needs defined above.

\section{References}

[1] C. Bentaleb and A. Louitri, "La construction de la croissance des PME au Maroc," Manag. Avenir, no. 3, pp. 77-81, (2011).

[2] BIT, Les petites et moyennes entreprises et la création d'emplois décents et productifs. Genève, (2015).

[3] O. Benaicha, "Les motivations des PME pour la RSE au Maroc," Congrès Int. Francoph. en Entrep. PME, (2014).

[4] A. Turki, "Les PME face à la RSE," La Rev. des Sci. Gest., no. 5, pp. 161-169, (2014).

[5] M. Bousseta and S. Kharbouche, "Responsabilité Sociale des Entreprises au Maroc," Rev. Marocaine Rech. en Manag. 
Mark., vol. 9-10, (2014).

[6] M. Reinfeldt and J. Boulejiouch, "Guide d'orientation pour la transition vers des Zones Industrielles Durables au Maroc à l'usage des acteurs des Zones Industrielles," Ministère Délégué Chargé de l'Environnement et GIZ, Rabat, Maroc, (2017).

[7] GIZ, "Guide méthodologique pour l'adaptation au changement climatique des zones industrielles," Eschborn, Allemagne, (2017).

[8] F. Aggeri and M. Cartel, "Le changement climatique et les entreprises : enjeux, espaces d'action, régulations internationales," Entrep. Hist., vol. 86, no. 1, pp. 6-20, (2017).

[9] J. Gobert, F. Rudolf, A. Kudriavtsev, and P. Averbeck, "L'adaptation des entreprises au changement climatique Questionnements théoriques et opérationnels.," Rev. d'Allemagne des Pays Lang. Allemande, vol. 49, no. 2, pp. 491-504, Jul. (2017).

[10] A. Goldstein, W. R. Turner, J. Gladstone, and D. G. Hole, "The private sector's climate change risk and adaptation blind spots," Nat. Clim. Chang., vol. 9, no. 1, pp. 18-25, (2019).

[11] CGEM, "Le secteur privé Marocain face aux défis et Opportunités liés au Changement Climatique : enjeux et recommandations," Casablanca, Maroc, (2019).

[12] MDE, "Rapport de la troisième Communication Nationale du Maroc à la Convention Cadre des Nations Unies sur les Changements Climatiques," Rabat, Maroc, (2016).

[13] GIZ, "Case study summary : Ait Melloul Industrial Zone," (2016).

[14] Y. Jaouhari, L. Stour, and A. Agoumi, "Mainstreaming of Climate Change Adaptation in Moroccan Companies: Tools, Teachings, and Perspectives BT - Handbook of Climate Change Management: Research, Leadership, Transformation," in Handbook of Climate Change Management, W. Leal Filho, J. Luetz, and D. Ayal, Eds. Cham: Springer International Publishing, (2021), pp. 1-33.

[15] IPCC, Climate Change 2014: Impacts, Adaptation, and Vulnerability. Part A: Global and Sectoral Aspects. Contribution of Working Group II to the Fifth Assessment Report of the Intergovernmental Panel on Climate Change. New York, USA: Cambridge University Press, (2014).

[16] B. Biagini and A. Miller, "Engaging the private sector in adaptation to climate change in developing countries: importance, status, and challenges," Clim. Dev., vol. 5, no. 3, pp. 242252, (2013).

[17] A. Guillou and V. Dépoues, Adaptation au changement climatique : comment passer à la vitesse supérieure. (2020).

[18] C. Strasser and H. Mewes, "Consultant's Manual : Developing a Climate Change Adaptation Strategy for Companies," Berlin/ New Delhi, (2013).
[19] GIZ, “L'adaptation du secteur privé au changement climatique (ASPCC) - Factsheet," (2016).

[20] ICT, "Strengthening competitiveness through climate resilience in international value chains (factsheet)," (2018).

[21] A. Bissay, P. Pernelle, A. Lefebvre, and A. Bouras, "approche de capitalisation des connaissances à l'aide d'un système plm," in 7th International Conference on Modelling and Simulation (MOSIM08), Paris, France, (2008).

[22] M. Lewkowicz and M. Zacklad, "Une approche de la capitalisation des connaissances: l'analyse des processus de prise de décision collective," Ingénierie des connaissances. Evol. récentes Nouv. défis. Paris Eyrolles, (2000).

[23] D. Conway et al., "The need for bottom-up assessments of climate risks and adaptation in climate-sensitive regions," Nat. Clim. Chang., vol. 9, no. 7, pp. 503-511, (2019).

[24] S. Hallegatte, "Strategies to adapt to an uncertain climate change," Glob. Environ. Chang., vol. 19, no. 2, pp. 240-247, (2009).

[25] P. Bowyer, S. Bender, D. Rechid, and M. Schaller, "Adapting to Climate Change: Methods and Tools for Climate Risk Management," Clim. Serv. Center, Ger., vol. 124, (2014).

[26] W. N. Adger et al., "Assessment of adaptation practices, options, constraints and capacity," in Climate change 2007: impacts, adaptation and vulnerability. Contribution of working group II to the fourth assessment report of the Intergovernmental Panel on Climate Change, Cambridge University Press, (2007), pp. 719743. 